\title{
Genetic Diversity in the 3' Terminal 4.7-kb Region of Grapevine leafroll-associated virus 3
}

\author{
Jinbo Wang, Abhineet M. Sharma, Siobain Duffy, and Rodrigo P. P. Almeida
}

First, second, and fourth authors: Department of Environmental Science, Policy and Management, University of California, Berkeley; and third author: Department of Ecology, Evolution and Natural Resources, School of Environmental and Biological Sciences, Rutgers University, New Brunswick, NJ.

Accepted for publication 2 November 2010 .

\section{ABSTRACT}

Wang, J., Sharma, A. M., Duffy, S., and Almeida, R. P. P. 2011. Genetic diversity in the 3' terminal 4.7-kb region of Grapevine leafroll-associated virus 3. Phytopathology 101:445-450.

Grapevine leafroll-associated virus 3 (GLRaV-3; Ampelovirus, Closteroviridae), associated with grapevine leafroll disease, is an important pathogen found across all major grape-growing regions of the world. The genetic diversity of GLRaV-3 in Napa Valley, CA, was studied by sequencing $4.7 \mathrm{~kb}$ in the $3^{\prime}$ terminal region of 50 isolates obtained from Vitis vinifera 'Merlot'. GLRaV-3 isolates were subdivided into four distinct phylogenetic clades. No evidence of positive selection was observed in the data set, although neutral selection (ratio of non- synonymous to synonymous substitution rates $=1.1$ ) was observed in one open reading frame (ORF 11, p4). Additionally, the four clades had variable degrees of overall nucleotide diversity. Moreover, no geographical structure among isolates was observed, and isolates belonging to different phylogenetic clades were found in distinct vineyards, with one exception. Considered with the evidence of purifying selection (i.e., against deleterious mutations), these data indicate that the population of GLRaV-3 in Napa Valley is not expanding and its effective population size is not increasing. Furthermore, research on the biological characterization of GLRaV-3 strains might provide valuable insights on the biology of this species that may have epidemiological relevance.
Genetic diversity studies provide insights into the ecology, evolution, and biology of viruses. Structured sampling of virus diversity can be used for various ecological purposes, such as the historical reconstruction of epidemics (1) and the estimation of the number of invasions into new regions (5). Virus sequence collections also provide insights into what processes are important in the dynamics of viral evolution (28), the selective pressures on genomes and genes (24), and the potential for the emergence of new genotypes (13). Furthermore, they allow for the grouping of isolates into clusters that may have unique biological characteristics. The distinct genetic strains may cause different disease symptoms in the same host plant; for instance, Citrus tristeza virus (CTV) can cause quick decline, stem pitting, or seedling yellows symptoms (23). Understanding genetic diversity is very important for the development of appropriate detection tools. In addition, the implementation of quarantine and other regulatory measures requires robust knowledge of taxon diversity so that only targeted pathogens are the focus of expensive, laborious, and often controversial efforts. Finally, effective virus control strategies based on RNA interference require the use of conserved viral sequences (33).

Grapevine leafroll-associated virus 3 (GLRaV-3), a member of the genus Ampelovirus (Closteroviridae), is a single-stranded positive-sense RNA virus with an $\approx 18 \mathrm{~kb}$ genome $(19,20)$. GLRaV-3 is associated with grapevine leafroll disease (GLRD), an economically important disease present in all grape-growing regions of the world $(3,6,9,19,22,25,32)$. Although previously

Corresponding author: R. P. P. Almeida

E-mail address: rodrigoalmeida@berkeley.edu

* The $\boldsymbol{e}$-Xtra logo stands for "electronic extra" and indicates that the online version contains one supplementary figure.

doi:10.1094/PHYTO-07-10-0173

(C) 2011 The American Phytopathological Society considered to be predominantly disseminated through infected plant material, interest in GLRaV-3 has increased in the last two decades after it was found to be vector transmitted (7) and to be spreading within vineyards $(3,4,12)$. Recently, it was also shown that the transmission of GLRaV-3 occurs in a semipersistent manner (30), and there is no evidence of virus-vector specificity for the transmission of GLRaV-3 (31). Although several other viruses, named sequentially as GLRaV-1, -2 , and so forth, are also associated with GLRD, GLRaV-3 appears to be the most widespread species worldwide in GLRD-affected plants $(3,10,11)$.

The degree of genetic diversity within GLRaV-3 is poorly understood. Only four whole genomes for isolates of GLRaV-3 have been sequenced $(6,14,16,19)$. The genomes of these isolates share general characteristics, with the exception that two of them have an extended 5' untranslated region (UTR) which, in fact, might be present in all GLRaV-3 (14). In the past, Turturo and colleagues (32) constructed phylogenetic trees using three genes from 45 GLRaV-3 isolates from various geographical areas. In their study, different genomic regions yielded distinct phylogenetic trees with two to three clades, and the authors also found evidence of recombination among those isolates. Studies with Brazilian and American isolates, on the other hand, indicated the possible presence of up to five GLRaV-3 clades $(8,9)$.

Viruses in the family Closteroviridae can be extremely diverse, genetically and phenotypically $(2,23)$. CTV, for example, has been well studied in this context and shows a large range of phenotypes in relation to plant pathogenicity, symptomatology, and transmission (23). In addition, analysis on different open reading frames (ORFs) has shown differential selective pressures on the CTV genome (27). Previous studies sequenced short $(<1,000 \mathrm{bp})$ contiguous fragments of the GLRaV-3 genome, limiting conclusions about the overall genomic diversity, recombination, and presence of variable selective pressures on different ORFs (32). A study using a larger fragment of GLRaV-3's 
genome would allow for a better understanding of its diversity and evolution. Additionally, distinct strains and their spatial distribution may be better identified. For that purpose, we amplified and sequenced a 4,711-nucleotide (nt) fragment in the $3^{\prime}$ terminal region of GLRaV-3 from 50 isolates obtained from symptomatic plants in the Napa Valley, CA.

\section{MATERIALS AND METHODS}

Samples. Petioles from Vitis vinifera 'Merlot' exhibiting GLRD symptoms (leaf rolling and reddening) were collected from five vineyards from late June to late October 2009 across Napa Valley, CA, labeled 3 and 6 to 9, followed by a sample number. The vineyards were located in a $16-\mathrm{km}$ corridor within the Napa Valley, encompassing major appellations in the region. Based on the spatial distribution of diseased plants (apparently random), no obvious evidence of vector spread of GLRaV-3 was found at these locations. Up to 20 independent petioles samples from different individual vines were collected at each vineyard. The samples were transported on ice, and $0.2-\mathrm{g}$ portions were frozen in liquid nitrogen before storage at $-80^{\circ} \mathrm{C}$ in $1.5-\mathrm{ml}$ microcentrifuge tubes. In addition, the Foundation Plant Services at the University of California, Davis, kindly provided virus source plant material (FPS virus accession number LR101 and LR109, labeled with $\mathrm{GH}_{\text {__ }}$ initials) and healthy grapevines (V. vinifera), which were used as controls in this study.

RNA extraction from leaf petioles. A modified version of an RNA extraction protocol for woody tissue as described by MacKenzie et al. (18) was used to extract high-quality RNA for reverse-transcription polymerase chain reaction (PCR). Then, $\approx 0.2 \mathrm{~g}$ of frozen petiole sample was finely ground in liquid nitrogen using a mortar and pestle. The sample was then poured into a 2-ml microcentrifuge tube and homogenized in $2 \mathrm{ml}$ of lysis buffer. Following sample homogenization, $120 \mu \mathrm{l}$ of $20 \%$ lauryl sarcosine was added, and samples were heated at $70^{\circ} \mathrm{C}$ for 10 min with periodic vortexing. After sample lysis, the Qiagen RNeasy Mini Kit (Germantown, MD) was used to continue extraction. The warmed lysate was added to the supplied Qiashredder column $(800 \mu \mathrm{l}$ maximum volume $)$ and spun at $16,000 \times g$ for $5 \mathrm{~min}$. The supernatant was then transferred into a new $1.5-\mathrm{ml}$ microcentrifuge tube, and $630 \mu \mathrm{l}$ of $100 \%$ ethanol was added. The manufacturer's instructions for plant and fungi extractions (RNeasy Mini Handbook) were followed. The quality and concentration of total RNA were tested upon elution using a Nanodrop ND-1000 Spectrophotometer (Wilmington, DE).

cDNA synthesis and PCR. A two-step protocol was used to synthesize and amplify a 4.8-kb fragment in the $3^{\prime}$ terminal region of the genome from the RNA template (Fig. 1). Because there was limited sequence data available for the $3^{\prime}$ terminal region of interest to this study, all primers were designed using conserved regions from three sequenced isolates $(6,16,19)$. Single-stranded cDNA was synthesized using the Superscript III Reverse Transcriptase Kit (no. 18080-085; Invitrogen, Carlsbad, CA) per the manufacturer's instructions using 2 pmol of sequence-specific primer 3-UTR-R1 (5' GACCTAACTTATTGTCGATAAGTTAGC CTC $3^{\prime}$ ) during the initial denaturing and annealing step. In addition to the Superscript III kit components, reverse-transcriptase reactions were supplemented with $40 \mathrm{U}$ of RNaseOut Recombinant RNase Inhibitor (no. 10777-019; Invitrogen) per the manufacturer's recommendation and carried out at $55^{\circ} \mathrm{C}$ for $60 \mathrm{~min}$, followed by an enzyme inactivation step of $70^{\circ} \mathrm{C}$ for 15 min. Upon completion of cDNA synthesis, 2 U of Ribonuclease H (no. 18021-071; Invitrogen) were added to remove template RNA and reactions were carried out according to the manufacturer's instructions.

The cDNA template was then amplified using the Finnzymes Phusion High-Fidelity DNA Polymerase in GC buffer (F-530L; Finnzymes, Espoo, Finland) with $2 \mu \mathrm{l}$ of cDNA, $0.5 \mu \mathrm{M}$ forward primer ORF-5-F1 (5' GCAGATCACGCTAGCATTATACACTA TA $3^{\prime}$ ), and $0.5 \mu \mathrm{M}$ reverse primer 3 -UTR-R1. After an initial denaturing step of $98^{\circ} \mathrm{C}$ for $30 \mathrm{~s}, 35$ cycles of PCR were carried out at $98^{\circ} \mathrm{C}$ for $7 \mathrm{~s}$ (denaturing), $57.5^{\circ} \mathrm{C}$ for $20 \mathrm{~s}$ (annealing), $72^{\circ} \mathrm{C}$ for $2 \min 24 \mathrm{~s}$ (extension), ending with a final extension at $72^{\circ} \mathrm{C}$ for $7 \mathrm{~min}$ and a $4{ }^{\circ} \mathrm{C}$ hold step. The PCR product was tested for the presence of a $4.8-\mathrm{kb}$ band by loading $3 \mu \mathrm{l}$ of sample in $1 \%$ agarose gel and visualizing on a UV transilluminator after ethidium bromide staining. An additional PCR step was performed using primers nested within the 4.8-kb amplicon to increase template quantity. Twenty-fold dilutions of the first PCR product were amplified using Finnzymes Phusion High-Fidelity DNA polymerase in HF buffer (F-530L; Finnzymes) with $0.5 \mu \mathrm{M}$ forward primer ORF-5-F4 (5' AAGACGAACGAAAACCA GGTTAC $3^{\prime}$ ) and $0.5 \mu \mathrm{M}$ reverse primer 3-UTR-R-5 (5' TAAG AGGCCCGCCTAGGTCCCAAAC 3'). Eight reactions per positive sample were run. After an initial denaturing step of $98^{\circ} \mathrm{C}$ for $30 \mathrm{~s}, 35$ cycles of PCR were carried out at $98^{\circ} \mathrm{C}$ for $7 \mathrm{~s}$ (denaturing), $67.5^{\circ} \mathrm{C}$ for $20 \mathrm{~s}$ (annealing), and $72^{\circ} \mathrm{C}$ for $2 \min 24 \mathrm{~s}$ (extension), ending with a final extension at $72^{\circ} \mathrm{C}$ for $7 \mathrm{~min}$ and a $4^{\circ} \mathrm{C}$ hold step. The PCR product was tested for the presence of a $4.79-\mathrm{kb}$ band by loading $3 \mu \mathrm{l}$ of sample in $1 \%$ agarose gel and visualizing on a UV transilluminator after ethidium bromide staining.

Sequencing and fragment assembly. Samples producing the 4.79-kb band after the second PCR were purified and sequenced. The eight reactions per sample were combined and purified using the Zymo Research DNA Clean \& Concentrator Kit (D4034; Zymo Research, Orange, CA). Sequencing reactions were set up by adding $239.5 \mathrm{ng}$ of DNA, 0.4 pmol primers from internally conserved sites within the $4.79-\mathrm{kb}$ amplicon, and diethylpyrocarbonate water to bring the total volume to $6 \mu \mathrm{l}$. Remaining reactions were carried out at the Barker Hall Sequencing Facility located on the University of California, Berkeley campus using an Applied Biosystems 96 capillary 3730xl DNA Analyzer (Applied Biosystems, Foster City, CA). Consensus sequences were assembled using Vector NTI (Invitrogen) with 2 to $3 \times$ coverage per strand yielding a consensus sequence $4,711 \mathrm{nt}$ in length. In all, 5 to 13 samples were successfully sequenced per vineyard, because not all samples collected with GLRD symptoms tested positive with the approach used here. For example, primer sets might not have been conserved enough to amplify certain genotypes, virus populations might have been low when samples were collected, or plants could be infected with other GLRaV

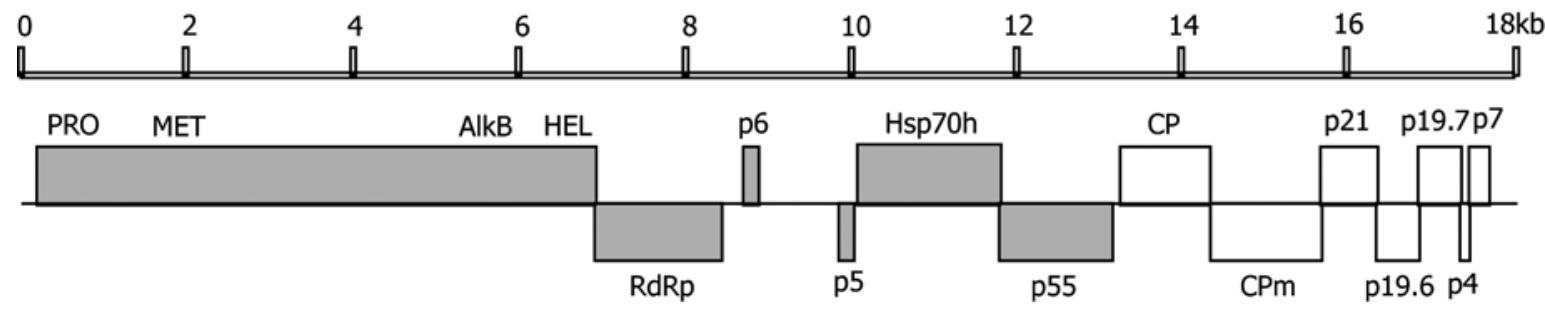

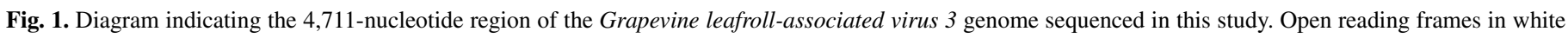
represent the sequenced region in the $3^{\prime}$ terminal region. 
species and not GLRaV-3. Accession numbers for deposited sequences obtained in this study are HQ130283 to HQ130332.

Phylogenetic analysis of $\mathbf{3}^{\prime}$ terminal region. Analyses included 50 field-collected and three greenhouse-maintained isolates, in addition to three sequenced GLRaV-3 genomes deposited in GenBank. Sequences were aligned by eye in Se-Al (http:// tree.bio.ed.ac.uk/software/seal/). Recombination was assessed with six algorithms (RDP, GENECONV, Bootscan, MaxChi, Chimaera, and 3Seq) implemented in RDP3.15 (21). Maximum likelihood phylogenetic analyses were conducted in PAUP* (29), with tree-bisection-reconnection branch swapping and nucleotide substitution models selected by AIC in MODELTEST (26). One thousand bootstrap replicates were run for each analysis.

Selection and diversity analyses. Selection on codons was determined by the single-likelihood ancestor-counting method as implemented by the datamonkey webserver (www.datamonkey.org). Negative, or purifying, selection on a codon means that mutations in that codon are being purged from the population, and that there is pressure to maintain the same sequence at that site. Nucleotide diversity $(\pi)$, the average pairwise difference between any two sequences, was determined by Nei and Li's method as implemented in DnaSP (15). The partitioning of the genetic variation among and between clades and vineyards was also assessed with DnaSP with the Fst fixation index. To determine the overall polymorphism among worldwide isolates of GLRaV-3, the average $\pi$ for portions of two genes that were well represented in GenBank was calculated. A 448-nt portion of ORF 4, the HSP70h gene, was used from 64 sequences (corresponding to nucleotides 11,000 to 11,447 in the reference sequence NC_004667). These included isolates from Chile, China, Israel, Italy, South Africa, Syria, Tunisia, and the United States: NC_004667, AJ748510AJ748524, DQ780885 to DQ780891, EU259806, EU344893, FJ195745 to FJ195749, FJ883760 to FJ883769, GQ246623, GQ478313, and GQ344807 to GQ344828. A 484-nt portion of the coat protein (CP) (ORF 6) was used from 34 sequences (corresponding to nucleotides 13,269 to 13,752 in NC_004667). These isolates were from Austria, Brazil, Chile, China, Greece, Israel, Italy, Nigeria, South Africa, Syria, Tunisia, and the United States: NC_004667, AJ606338 to AJ606358, AY753208, DQ062152, DQ119574, DQ680141, DQ680142, DQ911148, EU259806, EU344893 to EU344896, and FJ786016.

Phylogenetic analysis of $\mathbf{C P}$ gene. The analysis was conducted not only using the sequence data of the $3^{\prime}$ terminal region from the above but also including sequence data from other GLRaV-3 isolates, not included in this survey, that were originally collected in California vineyards ( $n=13$ : CP-1, 5, 6, 8, 14, 16; GH-3, 4, 8; LV89-01, 02; LR101, and LR109). Isolates in the CP series were obtained from Napa Valley vineyards and the other isolates were originally obtained from infected material maintained at the Foundation Plant Services of the University of California, Davis. Additionally, 32 sequences of the GLRaV-3 CP gene were downloaded from GenBank and used in the analyses.

\section{RESULTS}

Phylogeny of $\mathbf{3}^{\prime}$ terminal region. Four statistically supported clades were observed; those were arbitrarily labeled by adding letters at the end of GLRaV-3 (Fig. 2). Two sequenced isolates, $\mathrm{NY} 1$ and $\mathrm{Cl766}$, grouped together within clade GLRaV-3a, while the South African isolate GP18 fell into GLRaV-3b. Clades GLRaV-3b and -3d were vineyard specific (sites 3 and 7, respectively). Clades GLRaV-3a and $-3 \mathrm{c}$ had a combination of isolates from multiple vineyards. The moderate fixation index $(F s t=0.44)$ reflects the shared diversity among sites. No plant infections with multiple GLRaV-3 clades or different genotypes within the same plant were detected and no statistical evidence of recombination among the 50 vineyard isolates in this study was found. Trees for individual ORFs support this analysis (Supplementary Figure S1).
Diversity and selection. The average nucleotide diversity $(\pi)$ at all sites, except vineyard 3 (3:0.001), is comparable with the average diversity value 0.047 of the GLRV-3 CP worldwide (6:0.059, 7:0.044, 8:0.053, and 9:0.065). The overall nucleotide diversity of the 50 vineyard isolates in Napa Valley, CA was as great as those isolates previously sampled worldwide. In the direct comparison of the $\pi$ of the CP gene (ORF 6) from 34 global isolates with the sliding window analysis of the 50 vineyard isolates (Fig. 3), the Californian isolates were more polymorphic. Other portions of the genome showed larger amounts of polymorphism, especially near the $3^{\prime}$ end of the genome, p4 and p7 (ORFs 11 and 12, respectively). p4 is of interest, because it was found to be evolving neutrally: mean nonsynonymous/synonymous substitution rates ratio $\left(d_{\mathrm{N}} / d_{\mathrm{S}}\right) \approx 1$ (Table 1 ) (high ratios show positive selection, low ratios indicate purifying selection, and a ratio value $=1$ suggests that selection has little effect on the sequence). In addition, members of the GLRaV-3d clade would have to utilize an alternate start codon (ACG) to translate the ORF coding $\mathrm{p} 4$.

The diversity in the $3^{\prime}$ terminal region of GLRaV-3 does not appear to be driven by positive selection. There was substantial purifying selection operating on most of these ORFs (mean $d_{\mathrm{N}} / d_{\mathrm{S}}$ $\leq 0.36$ for all but $\mathrm{p} 4$ and $\mathrm{p} 7$ ) (Table 1 ), and no positively selected sites were detected. The amount of diversity within each of the GLRaV-3 clades identified here was variable (Table 2) but conclusions based on these data are limited due to the small sample size. However, GLRaV-3b and $-3 c$ had the same number of

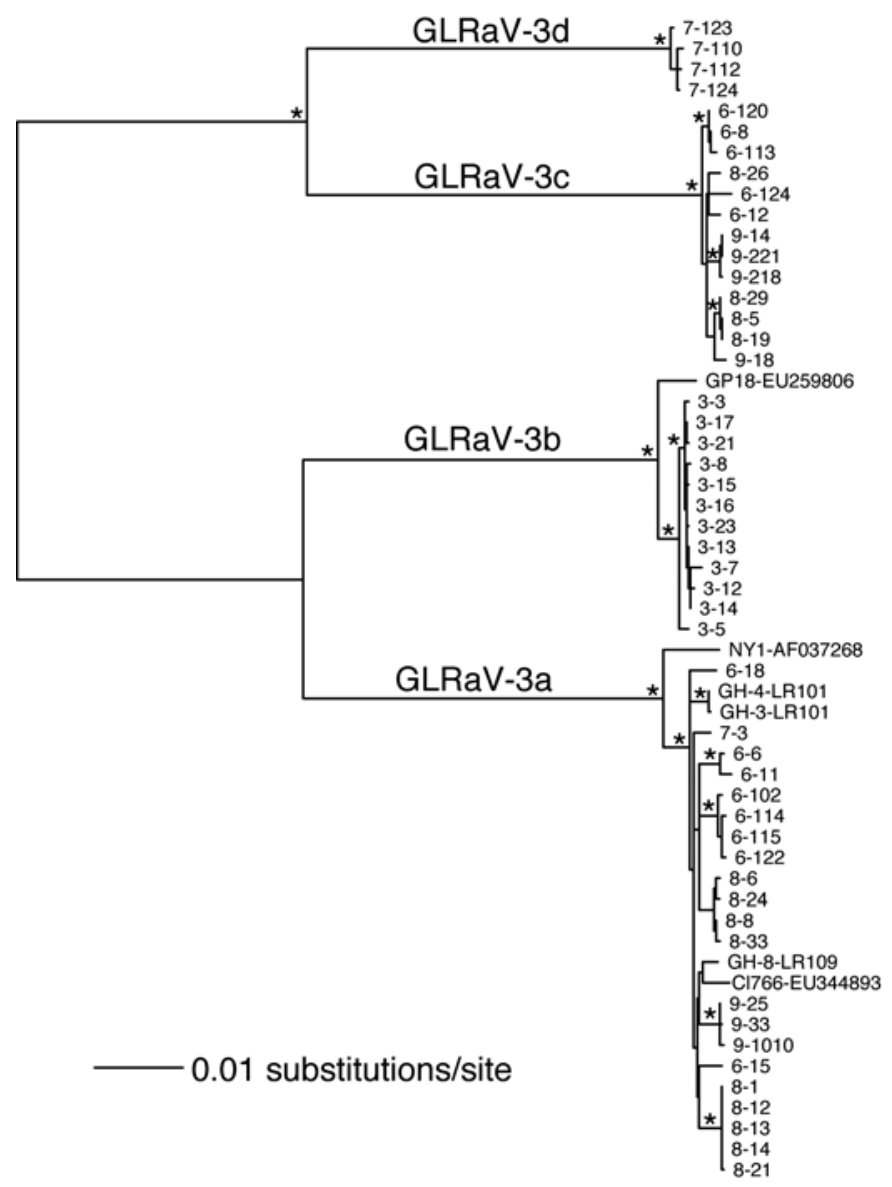

Fig. 2. Maximum likelihood tree of 4,711-nucleotide portion of the $3^{\prime}$ end of the genome of Grapevine leafroll-associated virus 3 (GLRaV-3) from five vineyards in California (vineyards 3 and 6 to 9), greenhouse-maintained grapevines (GH-3, GH-4, and GH-8), and three previously sequenced isolates from the United States (NY1), South Africa (GP18), and Chile (C1766). The tree is midpoint rooted for clarity of presentation and asterisks indicate $\geq 90 \%$ branch support. 
samples but GLRaV-3c had almost three times the $\pi$ value compared with GLRaV-3b. Because GLRaV-3b was found in only one vineyard, the smaller $\pi$ for that clade is interpreted as a consequence of these isolates having been sampled from one site alone.

Phylogeny of GLRaV-3 CP gene. The phylogenetic tree obtained with the CP gene (Fig. 4), which includes sequence data from worldwide isolates, showed topology similar to the tree with the $3^{\prime}$ terminal region of GLRaV-3. The same four statistically supported clades were detected. Most isolates clustered within the GLRaV-3a clade, followed by GLRaV-3b. None of the previously known isolates belonged to GLRaV-3d, with the exception of four sequenced in this study, suggesting that these represent a new strain of this virus. One sequence from Chile (EU344894) may also represent an additional genotypic cluster of GLRaV-3, although that branch was not well supported in this analysis (bootstrap support of 76 and 78 with respect to sister clades). Another sequence, AJ606354, had limited evidence of recombination, which could explain its placement in the tree. Finally, the Napa Valley in California had isolates belonging to all four main groups of GLRaV-3 (Figs. 2 and 4).

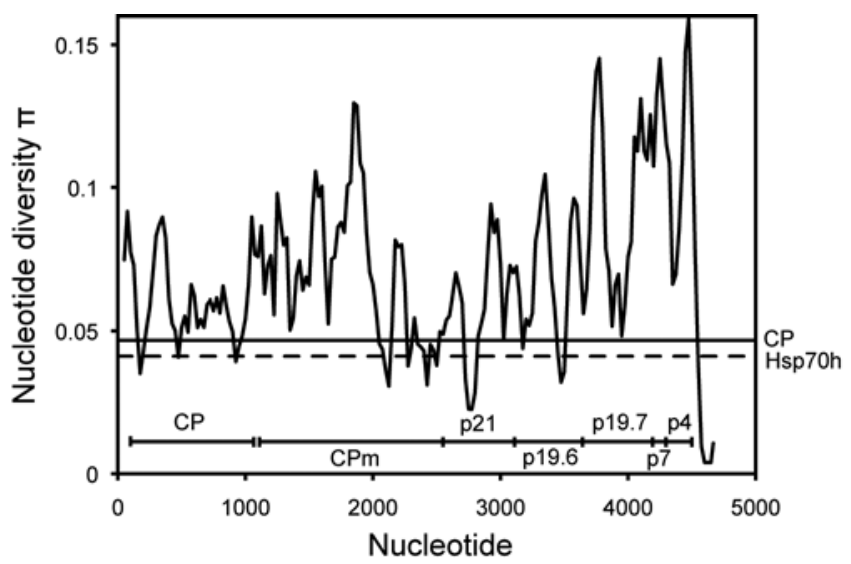

Fig. 3. Sliding window analysis (100-by-25-nucleotide [nt] steps) of the nucleotide diversity $(\pi)$ of the sequenced 4,711-nt region from the 50 vineyard isolates is shown as the jagged solid line. Positions of the seven open reading frames (ORFs) within this region are shown above the x-axis. Average nucleotide diversity of the global population of Grapevine leafroll-associated virus 3 from a portion of the HSP70h gene (64 taxa, a 448-nt region of ORF 4) and the coat protein gene (34 taxa, a 483-nt region of ORF 6) are shown as the dashed and solid horizontal lines, respectively. The average $\pi$ of the 50 vineyard isolates over the $4,711 \mathrm{nt}$ was 0.070 .

TABLE 1. Evidence of purifying selection $(P<0.05)$ on codons in the seven sequenced Grapevine leafroll-associated virus 3 open reading frames (ORFs)

\begin{tabular}{lccc}
\hline ORFs $^{\mathrm{a}}$ & Average $d_{\mathrm{N}} / d_{\mathrm{S}}{ }^{\mathrm{b}}$ & Positively selected sites & Negatively selected sites \\
\hline CP & 0.12 & - & 144,216 \\
CPm & 0.28 & - & $6,346,402$ \\
p21 & 0.15 & - & 15,124 \\
p19.6 & 0.34 & - & 100 \\
p19.7 & 0.36 & - & 21 \\
p4 & 1.11 & - & - \\
p7 & 0.46 & - & 7 \\
\hline
\end{tabular}

a $\mathrm{CP}=$ coat protein

${ }^{\mathrm{b}}$ Mean nonsynonymous/synonymous substitution rates ratio.

TABLE 2. Nucleotide diversity within Grapevine leafroll-associated virus 3 (GLRaV-3) clades identified in this study

\begin{tabular}{lcc}
\hline Phylogenetic group & Nucleotide diversity & No. of isolates \\
\hline GLRaV-3a & 0.0048 & 26 \\
GLRaV-3b & 0.0011 & 13 \\
GLRaV-3c & 0.0030 & 13 \\
GLRaV-3d & 0.0012 & 4 \\
All groups & 0.0702 & 56 \\
\hline
\end{tabular}

\section{DISCUSSION}

The genetic diversity of a 4.7-kb fragment in the $3^{\prime}$ terminal region of GLRaV-3 was analyzed. This represents almost $26 \%$ of the $\approx 18-\mathrm{kb}$ genome of GLRaV-3. The data set based on the California isolates and sequenced GLRaV-3 genomes showed that there are at least four distinct and well-supported clades of GLRaV-3. These clades were also well supported by phylogenetic trees generated for each one of the seven ORFs within the 4.7-kb genome fragment. Other studies on the variability of different GLRaV-3 genes also showed the presence of multiple genotypic clusters in the species, although results were gene dependent $(6,8,9,32)$. Turturo et al. (32), for example, analyzed GLRaV-3 genetic variability from 45 isolates collected around the world by

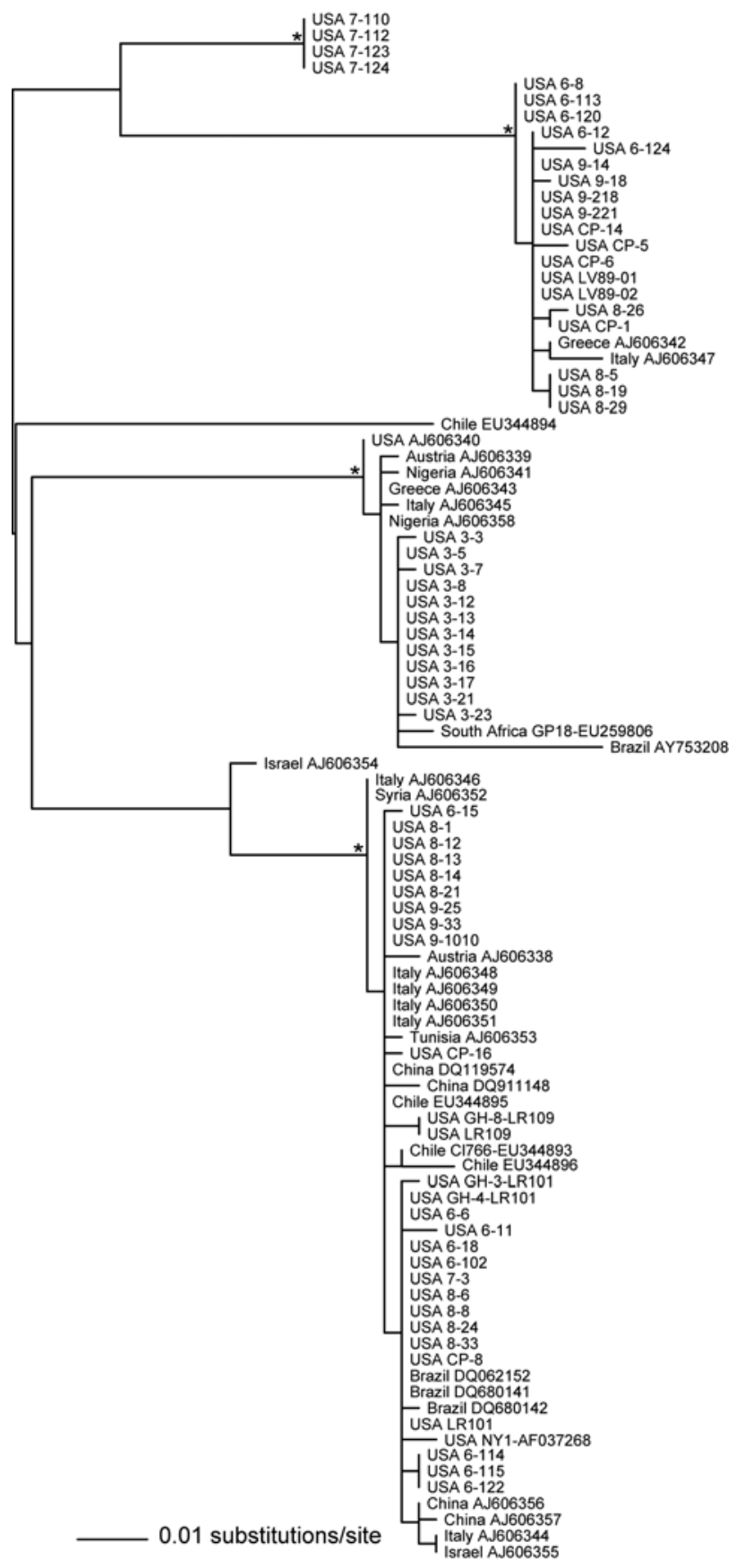

Fig. 4. Maximum likelihood tree of 405 nucleotides (nt) of the 939-nt coat protein gene of Grapevine leafroll-associated virus 3, including isolates previously sequenced and those generated in this study. The tree is midpoint rooted, and asterisks indicate $\geq 90 \%$ branch support. The country where samples were collected is shown before the accession number of each sequence. 
sequencing three genes; they found contradictory trees for the genes and isolates from the same plant. The most likely explanations for those results were the presence of recombination or mixed GLRaV-3 infections; however, tree incongruence limited careful analysis of genetic diversity among isolates. Because GLRaV-3 has a large genome $(\approx 18 \mathrm{~kb})$, generating whole genome sequences for diversity studies is technically challenging, especially when considering the potential for multiple infections within one plant. The approach used here allowed for the amplification and sequencing of a 4.7-kb fragment of GLRaV-3 while overcoming some of the limitations to analyze the genetic diversity of this virus. No multiple GLRaV-3 infections were detected in this study but that was expected, given the amplification protocol used in this study and, therefore, it is possible that mixed infections of different GLRaV-3 isolates within a single plant were present in the samples but were not detected. No statistical evidence of recombination among the 50 vineyard isolates was found.

Phylogenetic analysis of the CP gene of GLRaV-3 isolates from Napa Valley and worldwide samples provided a similar overview of the genetic diversity. The same four well-supported genetic clades were observed, and one of them was unique to this study (GLRaV-3d). In addition, one isolate from Chile (EU344894) did not group into any of these clades, suggesting that novel genotypes of GLRaV-3 would likely be found in future surveys. It is worth mentioning that this survey was based on a relatively small number of isolates from only one grape cultivar, yet it still recovered most of the GLRaV genotypes previously identified. Thus, more thorough investigations of GLRaV-3 diversity would be warranted. Other studies have also shown a lack of GLRaV-3 geographical structure $(9,32)$, similar to our results, indicating that transportation and use of infected plant material have been important in the dissemination of this pathogen. The amount of diversity within each of the GLRaV-3 clades identified here was variable, although a larger data set is necessary for a more robust analysis. Additionally, nucleotide diversity at the $3^{\prime}$ terminus of GLRaV-3 (i.e., in p4 and p7) was larger than at the HSP70h and $\mathrm{CP}$ genes. CTV has also been shown to have variable levels of diversity at different regions of its genome (17), indicating that Closterovirus spp. may have variable levels of nucleotide diversity depending on the genome region or gene in question. Future work should address this question in more detail, because these analyses included approximately a quarter of its genome and comparisons with the $5^{\prime}$ terminal region were not performed. Within the fragment sequenced, no evidence for positive selection in any of the ORFs analyzed was found, similar to previous observations with GLRaV-3 (32) and CTV (23). p4 (ORF 11) was found to be under neutral selection; future work on the function of p4 is warranted.

The absence of positive selection and evidence of purifying selection indicate that the four GLRaV-3 strains identified have been present in Napa Valley for some time and that they are not increasing in prevalence in the region. In addition, GLRaV-3 was diverse and showed little spatial structure, suggesting frequent migration among vineyards. Leafroll disease has been present in the region for several decades and, until recently, disease spread was assumed to occur primarily through infected plant material (10). Evidence of leafroll spread in Napa Valley (10) and other regions of the world $(3,12)$ mediated by insect vectors complicate the interpretation of our results. It is possible that the spatial genetic structure observed in this study is a consequence of the establishment of new vineyards with virus-infected plant material, possibly with mixed infections, followed by vector spread of the pathogen within and among vineyards. A large structured survey of infected grapevines will be necessary to generate more detailed information about GLRaV-3 distribution in Napa Valley and potentially split the historical (infected plant material) from current (vector transmission) factors driving disease spread. Based on the sequence data generated in this work, there is no evidence that any of these GLRaV-3 strains are increasing in prevalence in the region. Finally, because GLRaV-3 is a positive-strand RNA virus, extensive variability is expected in genetic diversity studies. The phylogenetic pattern observed, with multiple clades separated by long branches, indicates selective processes driving genotypes to fitness peaks.

\section{ACKNOWLEDGMENTS}

S. Duffy acknowledges support from the Rutgers School of Environmental and Biological Sciences and the New Jersey Agricultural Experiment Station. This research was supported by an award from the United States Department of Agriculture NIFA-SCRI (award no. 200951181-06027). We thank M. Cooper for assistance with sample collecting and M. Wong and S. Zhang for technical assistance with sequencing of isolates.

\section{LITERATURE CITED}

1. Almeida, R. P. P., Bennett, G. M., Anhalt, M. D., Tsai, C. W., and O'Grady, P. 2009. Spread of an introduced vector-borne banana virus in Hawaii. Mol. Ecol. 18:136-146.

2. Bertazzon, N., Borgo, M., Vanin, S., and Angelini, E. 2010. Genetic variability and pathological properties of Grapevine leafroll-associated virus 2 isolates. Eur. J. Plant Pathol. 127:185-197.

3. Cabaleiro, C., Couceiro, C., Pereira, S., Cid, M., Barrasa, M., and Segura, A. 2008. Spatial analysis of epidemics of Grapevine leafroll associated virus-3. Eur. J. Plant Pathol. 121:121-130.

4. Charles, J. G., Froud, K. J., van den Brink, R., and Allan, D. J. 2009. Mealybugs and the spread of grapevine leafroll-associated virus 3 (GLRaV-3) in a New Zealand vineyard. Australas. Plant Pathol. 38:576583.

5. Duffy, S., and Holmes, E. C. 2007. Multiple introductions of the Old World begomovirus Tomato yellow leaf curl virus into the New World. Appl. Environ. Microbiol. 73:7114-7117.

6. Engel, E. A., Girardi, C., Escobar, P. F., Arredondo, V., Dominguez, C., Perez-Acle, T., and Valenzuela, P. D. 2008. Genome analysis and detection of a Chilean isolate of Grapevine leafroll associated virus-3. Virus Genes 37:110-118.

7. Engelbrecht, D., and Kasdorf, G. 1990. Transmission of grapevine leafroll disease and associated closteroviruses by the vine mealybug, Planococcus ficus. Phytophylactica 22:341-346.

8. Fajardo, T. V. M., Dianese, E. C., Eiras, M., Cerqueira, D. M., Lopes, D. B., Ferreira, M. A. S. V., and Martins, C. R. F. 2007. Variability of the coat protein gene of Grapevine leafroll-associated virus 3 in Brazil. Fitopatol. Bras. 32:335-340.

9. Fuchs, M., Martinson, T. E., Loeb, G. M., and Hoch, H. C. 2009. Survey of the three major leafroll disease-associated viruses in Finger Lakes vineyards in New York. Plant Dis. 93:395-401.

10. Golino, D. A., Weber, E., Sim, S., and Rowhani, A. 2008. Leafroll disease is spreading rapidly in a Napa Valley vineyard. Calif. Agric. 62:156-160.

11. Habili, N., Fazeli, C., Ewart, A., Hamilton, R., Cirami, R., Saldarelli, P., Minafra, A., and Rezaian, M. 1995. Natural spread and molecular analysis of grapevine leafroll-associated virus 3 in Australia. Plant Dis. 85:14181422.

12. Habili, N., and Nutter, F. 1997. Temporal and spatial analysis of grapevine leafroll-associated virus 3 in Pinot Noir grapevines in Australia. Plant Dis. 81:625-628.

13. Holmes, E. C. 2010. The comparative genomics of viral emergence. Proc. Natl. Acad. Sci. USA 107:1742-1746.

14. Jarugula, S., Gowda, S., Dawson, W. O., and Naidu, R. A. 2010. 3'Coterminal subgenomic RNAs and putative cis-acting elements of Grapevine leafroll-associated virus 3 reveals 'unique' features of gene expression strategy in the genus Ampelovirus. Virol. J. 7:180.

15. Librado, P., and Rozas, J. 2009. DnaSP v5: A software for comprehensive analysis of DNA polymorphism data. Bioinformatics 25:1451-1452.

16. Ling, K. S., Zhu, H. Y., and Gonsalves, D. 2004. Complete nucleotide sequence and genome organization of Grapevine leafroll-associated virus 3, type member of the genus Ampelovirus. J. Gen. Virol. 85:2099-2102.

17. Lopez, C., Ayllon, M., Navas-Castillo, J., Guerri, J., Moreno, P., and Flores, R. 1998. Molecular variability of the 5' and $3^{\prime}$ terminal regions of citrus tristeza virus RNA. Phytopathology 88:685-691.

18. MacKenzie, D. J., McLean, M. A., Mukerji, S., and Green, M. 1997. Improved RNA extraction from woody plants for the detection of viral pathogens by reverse transcription-polymerase chain reaction. Plant Dis. $81: 222-226$.

19. Maree, H. J., Freeborough, M. J., and Burger, J. T. 2008. Complete 
nucleotide sequence of a South African isolate of grapevine leafrollassociated virus 3 reveals a 5' UTR of 737 nucleotides. Arch. Virol. 153:755-757.

20. Martelli, G., Agranovsky, A., Bar-Joseph, M., Boscia, D., Candresse, T., Coutts, R., Dolja, V., Falk, B., Gonsalves, D., Jelkmann, W., Karasev, A., Minafra, A., Namba, S., Vetten, H., Wislter, G., and Yoshikawa, N. 2002. The family Closteroviridae revised. Arch. Virol. 147:2039-2044.

21. Martin, D. P., Williamson, C., and Posada, D. 2005. RDP2: Recombination detection and analysis from sequence alignments. Bioinformatics 21:260-262.

22. Martin, R. R., Eastwell, K. C., Wagner, A., Lamprecht, S., and Tzanetakis, I. E. 2005. Survey for viruses of grapevine in Oregon and Washington. Plant Dis. 89:763-766.

23. Moreno, P., Ambros, S., Abiach-Marti, M., Guerri, J., and Pena, L. 2008. Citrus tristeza virus: A pathogen that changed the course of the citrus industry. Mol. Plant Pathol. 9:251-268.

24. Pagan, I., and Holmes, E. C. 2010. Long-term evolution of the Luteoviridae: Time scale and mode of virus speciation. J. Virol. 84:61776187.

25. Pietersen, G. 2007. Tackling the grapevine leafroll disease problem in South Africa. South Afr. J. Sci. 103:II.

26. Posada, D., and Crandall, K. A. 1998. MODELTEST: Testing the model of DNA substitution. Bioinformatics 14:817-818.
27. Rubio, L., Ayllon, M. A., Kong, P., Fernandez, A., Polek, M., Guerri, J., Moreno, P., and Falk, B. W. 2001. Genetic variation of Citrus tristeza virus isolates from California and Spain: Evidence for mixed infections and recombination. J. Virol. 75:8054-8062.

28. Simmons, H. E., Holmes, E. C., and Stephenson, A. G. 2008. Rapid evolutionary dynamics of Zucchini yellow mosaic virus. J. Gen. Virol. 89:1081-1085.

29. Swofford, D. L. 2001. PAUP*: Phylogenetic Analysis Using Parsimony (*and Other Methods), Beta Version 4.0b8. Sinauer Associates, Sunderland, MA.

30. Tsai, C. W., Chau, J., Fernandez, L., Bosco, D., Daane, K. M., and Almeida, R. P. P. 2008. Transmission of Grapevine leafroll-associated virus 3 by the vine mealybug (Planococcus ficus). Phytopathology 98:1093-1098.

31. Tsai, C. W., Rowhani, A., Golino, D. A., Daane, K. M., and Almeida, R. P. P. 2010. Mealybug transmission of grapevine leafroll viruses: An analysis of virus-vector specificity. Phytopathology 100:830-834.

32. Turturo, C., Saldarelli, P., Yafeng, D., Digiaro, M., Minafra, A., Savino, V., and Martelli, G. P. 2005. Genetic variability and population structure of Grapevine leafroll-associated virus 3 isolates. J. Gen. Virol. 86:217224.

33. Vance, V., and Vaucheret, H. 2001. RNA silencing in plants-defense and counterdefense. Science 292:2277-2280. 